\title{
Política Fiscal Assimétrica: 0 Caso do Brasil
}

\author{
Roberta Moreira Wichmann*, Marcelo Savino Portugal ${ }^{\dagger}$
}

\author{
Conteúdo: 1. Introdução; 2. Fontes de assimetria fiscal; 3. Metodologia; 4. Conclusão; \\ A. Apêndice. \\ Palavras-chave: Política fiscal; Assimetria; Modelo autorregressivo com mudança markovianas. \\ Códigos JEL: $\quad$ E63, E32, C32, C34.
}

Este artigo avaliou a existência de assimetrias nas respostas da política econômica no Brasil entre 2001 e 2010, verificando o comportamento das políticas fiscal (componentes de regra e discrição) e monetária ao longo do ciclo econômico. Para tanto, realizou uma análise descritiva preliminar e utilizou modelos autorregressivos com mudanças markovianas (MS-VAR). A análise preliminar revelou indícios de assimetria, com as políticas comportando-se de forma distinta nos diferentes cenários. Os modelos MS-VAR confirmaram esse resultado, mostrando que a regra é mais veloz e menos assimétrica que as demais políticas. Já a política monetária responde mais fortemente às variações positivas do hiato.

This paper evaluated the existence of asymmetries in economic policy responses in Brazil between 2001 and 2010, checking the behavior of the components of fiscal (rule and discretion components) and monetary policies over the business cycle. To do so, it conducted a preliminary descriptive analysis and estimated Markov-switching autoregressive models (MS-VAR). The preliminary analysis showed evidence of nonlinearity, with the policies behaving differently when facing different scenarios. The MS-VAR models have confirmed this result, showing that the rule is faster and less asymmetric than the other policies. Monetary policy, in turn, reacts more strongly to positive changes of the gap.

\footnotetext{
* Doutora pela Universidade Federal do Rio Grande do Sul (UFRGS). E-mail: roberta. wichmann@ufrgs .br

${ }^{\dagger}$ Professor dos Programas de Pós-Graduação em Economia (PPGE) e em Administração (PPGA) da Universidade Federal do Rio Grande do Sul (UFRGS) e Pesquisador do CNPq. E-mail: msp@ufrgs . br
} 


\section{INTRODUÇÃO}

O debate acerca da viabilidade e da eficácia da política fiscal como instrumento estabilizador das flutuações do produto continua em discussão, sendo que a crise econômica internacional iniciada em 2008 amplificou consideravelmente sua importância. Isso ocorreu, pois grande parte das economias centrais praticamente exauriu seu instrumental (ortodoxo) de política monetária, ou seja, suas taxas de juros já estavam muito próximas de zero, ${ }^{1}$ assim, evidenciou-se ainda mais a importância da política fiscal.

Normalmente, espera-se que a autoridade fiscal apresente um comportamento contracíclico, ao menos em episódios de recessão (Claessens et alii, 2008). Idealmente, o governo deveria agir contraciclicamente sempre, pois o sendo apenas na recessão, a relação dívida/PIB cresceria ao longo do tempo.

A política fiscal é dita contracíclica quando o governo eleva seus gastos durante episódios de desaceleração ou quando os reduz durante períodos de aceleração da economia, contribuindo, dessa forma, para suavizar as flutuações do produto (OCDE, 2003). ${ }^{2}$ Conforme observam Alesina et alii (2008, p. 1006-1007):

Most economists agree with the normative prescription that tax rates and discretionary government spending as a fraction of GDP ought to remain constant over the business cycle. If governments respected these prescriptions, we should observe a countercyclical pattern in fiscal policy. Namely, during a boom, (i) total government spending as a share of GDP should go down because of automatic stabilizers (if discretionary spending remained constant in real terms, the effect would be reinforced); (ii) with constant tax rates and some degree of progressivity, government revenues as a share of GDP should go up (the effect would be reinforced by tax cuts in recessions and tax increases in boom.); (iii) as a result, budget surpluses as a share of GDP should increase. The opposite should occur in recessions.

De acordo com Alesina et alii (2008), enquanto que nos países da OCDE verifica-se, geralmente, um comportamento fiscal contracíclico, em grande parte dos países em desenvolvimento verifica-se uma política fiscal predominantemente procíclica (no sentido de que os gastos do governo, como proporção do PIB, crescem durante episódios de aceleração econômica e decrescem durante episódios de desaceleração).

Gavin e Perotti (1997), utilizando dados anuais compreendidos entre 1970 e 1995, estudaram o comportamento dos gastos governamentais das economias latino-americanas. Os autores concluíram que, no período analisado, tais gastos foram moderadamente procíclicos durante as expansões e foram fortemente contracíclicos durante as recessões.

Ilzetzki e Végh (2008) apresentam duas explicações para o comportamento procíclico dos países em desenvolvimento. A primeira delas diz respeito à existência de imperfeições nos mercados de crédito internacionais que impedem os países em desenvolvimento de obterem empréstimos em tempos ruins devido, por exemplo, a problemas de credibilidade. ${ }^{3}$ Uma forma de corrigir tal imperfeição seria a adoção pelo governo de políticas suficientemente anticíclicas durante períodos de crescimento, com o intuito de sinalizar ao mercado seu compromisso em estabilizar o ciclo econômico. Com isso, o problema da credibilidade poderia ser reduzido.

\footnotetext{
${ }^{1}$ Esse fenômeno é conhecido na literatura como o problema do limite inferior zero (no inglês, zero lower bound). Maiores detalhes podem ser encontrados em Orphanides e Wieland (1998) e Reifschneider e Williams (1999).

${ }^{2}$ Esta mesma definição pode ser estendida à política monetária, ou seja, uma política monetária contracíclica é aquela onde há um afrouxamento durante episódios recessivos e um aperto em episódios de aceleração econômica e é procíclica quando realiza um afrouxamento/aperto durante episódios de aceleração/desaceleração.

${ }^{3}$ Esse tipo de argumentação pode ser encontrada em Gavin e Perotti (1997), Caballero e Krishnamurthy (2004), Mendoza e Oviedo (2006).
} 
A outra explicação dada por Ilzetzki e Végh (2008) seria a possibilidade de que em tempos de bom desempenho da economia ocorreria uma tendência à libertinagem fiscal. ${ }^{4}$ Os autores observam que com o grande número de trabalhos chegando a conclusões semelhantes, a prociclicidade da política fiscal em países em desenvolvimento se tornou parte do conhecimento convencional.

Ao analisar-se o comportamento da política econômica, seja ela fiscal ou monetária, é importante que se tenha em mente que a mesma possui componentes automáticos e discricionários ${ }^{5}$ e que estes podem apresentar comportamentos distintos, de forma que é possível que a prociclicidade esteja presente em apenas um dos componentes. Por exemplo, existe a possibilidade de que o componente de regra seja contracíclico e o componente discricionário seja procíclico.

Além disso, a fase do ciclo em que a economia se encontra (aceleração ou desaceleração) também deve ser levada em consideração. Se a política de estabilização deve ser coerente com a sustentabilidade fiscal, então o comportamento cíclico das variáveis fiscais deveria ser simétrico para que o déficit extra acumulado em tempos ruins fosse compensado nos bons tempos.

Porém, os formuladores de política econômica, quando utilizam instrumentos fiscais, podem responder, por exemplo, de forma procíclica apenas durante períodos de crescimento econômico, fazendo surgir então uma assimetria, ou seja, as variáveis fiscais reagiriam assimetricamente ao ciclo de negócios. Em outras palavras, os déficits aumentariam em períodos de recessão, mas não cairiam em períodos de crescimento.

Diversos fatores podem contribuir para o surgimento de assimetrias. De acordo com Sorensen e Yosha (2001), assimetrias na política fiscal podem surgir, como por exemplo,

(1) as restrições no mercado de crédito durante períodos recessivos,

(2) os arranjos institucionais que impedem o endividamento em excesso,

(3) a ausência de disciplina fiscal durante episódios de aceleração e,

(4) a tentativa, por parte dos partidos políticos, de influenciar os padrões de voto ou a performance de governos futuros.

Dessa forma, ao levar em consideração a questão da não linearidade, vê-se que a identificação do comportamento fiscal (pró ou contracíclico) não é tão simples, sendo necessária uma avaliação mais profunda, principalmente em países em desenvolvimento como o Brasil.

Balassone et alii (2008) procuraram verificar a presença de assimetria no comportamento da política fiscal em situações de aceleração e desaceleração do produto em 14 países da União Européia e, em seguida, tentaram identificar quais itens orçamentários foram responsáveis por tal assimetria. Utilizando dados anuais compreendidos entre 1970 e 2004 e empregando diversos métodos para dados em painel, os autores encontraram assimetrias significantes nas variáveis fiscais, sendo os gastos dos governos os responsáveis por tal fenômeno.

Hercowitz e Strawczynski (2004) estudaram o papel exercido pelo ciclo de negócios na elevação dos gastos dos governos dos países da OCDE no período entre 1975 e 1998. Os autores testaram econometricamente (utilizando dados em painel) a hipótese de que gastos governamentais assimétricos foram responsáveis pela elevação cíclica dos gastos dos governos. Hercowitz e Strawczynski (2004) concluíram que a razão gastos/PIB se elevou durante as recessões e não diminuiu o suficiente durante as acelerações, o que acabou favorecendo o aumento prolongado dos gastos nos países da OCDE após 1974.

Sorensen e Yosha (2001) examinaram o comportamento da política fiscal dos estados norte americanos, tentando identificar a existência de assimetrias, bem como suas fontes. Para tanto, utilizaram

\footnotetext{
${ }^{4}$ Tornell e Lane (1999), Talvi e Végh (2005), Alesina et alii (2008) e Ilzetzki (2008).

${ }^{5} \mathrm{O}$ componente automático responde mecanicamente à evolução do ciclo econômico. Já o componente discricionário é considerado circunstancial, ou seja, adotado quando considerado necessário.
} 
dados anuais entre 1963 e 1998 para os 48 estados continentais americanos. Os autores concluíram que as receitas e as despesas estaduais apresentaram assimetria significativa ao longo do ciclo econômico. Porém, ao analisarem o balanço fiscal, uma assimetria menos intensa foi identificada. Para Sorensen e Yosha (2001) a fonte da assimetria está aparentemente relacionada a existência de regras fiscais.

Rocha (2009) analisou a relação entre o ciclo econômico e as finanças públicas no Brasil entre 1995 e 2005, para tanto, separou as mudanças no saldo fiscal em duas partes, uma sendo resultante de políticas discricionárias e a outra sendo associada com os estabilizadores automáticos, realizando, em seguida, uma série de estimações e testes econométricos. A autora concluiu que não houve uma tentativa deliberada e sistemática por parte das autoridades fiscais de estabilizar a economia ao longo do ciclo usando políticas discricionárias e que a política fiscal se tornou menos procíclica após a implementação da Lei de Responsabilidade Fiscal. Além disso, a política fiscal apresentou um comportamento simétrico ao longo do ciclo econômico.

Rocha e Giuberti (2008) estudaram o comportamento fiscal dos estados brasileiros, investigando se a política fiscal se comportou de maneira contracíclica. Utilizando dados anuais para o período 1997-2004, as autoras estimaram modelos com dados em painel e obtiveram evidências de que a política fiscal dos governos estaduais se comportou de maneira procíclica. Os autores analisaram também os efeitos da adoção da Lei de Responsabilidade Fiscal sobre a política fiscal, concluindo que com a implementação da lei, as políticas conduzidas pelos governos estaduais continuaram procíclicas, mas em menor magnitude e de forma simétrica.

Diante dessa discussão, o presente artigo tem como objetivo geral analisar o comportamento da política fiscal brasileira e seus componentes a fim de verificar se a mesma apresenta assimetrias. Ou seja, é verificado se o comportamento dos componentes da política fiscal é dependente do ciclo econômico. A assimetria, aqui considerada, diz respeito à questão da direção, da velocidade e da dimensão das respostas fiscais durante as diversas fases do ciclo de negócios.

Como objetivos específicos, este artigo: (1) realiza uma modelagem econométrica do comportamento da política fiscal e de seus componentes considerando a presença de possíveis assimetrias na sua condução e (2) investiga em quais cenários a assimetria pode se manifestar.

\section{FONTES DE ASSIMETRIA FISCAL}

Sorensen e Yosha (2001) apontam alguns fatores que podem contribuir para o surgimento de assimetrias na política fiscal, como por exemplo, as restrições de crédito, as barreiras institucionais, a voracidade política e o ciclo eleitoral.

A definição de assimetria, aqui utilizada, está relacionada à questão da dependência da política fiscal em relação ao ciclo de negócios. Durante períodos de aceleração espera-se que o governo aja de forma contracíclica adotando uma política fiscal contracionista, enquanto que o inverso deveria ser verificado durante desacelerações. Porém esse comportamento nem sempre é observado. Dessa forma, uma política é considerada assimétrica quando suas características dependem da fase do ciclo de negócios onde a economia se encontra.

\subsection{Restrições de Crédito}

Conforme observam Gavin e Perotti (1997), durante períodos de desaceleração os formuladores de política fiscal podem sofrer perda de confiança por parte dos detentores do crédito, elevando as restrições à tomada de empréstimos. Sem acesso ao mercado de crédito torna-se mais difícil adotar políticas contracíclicas.

Isso explica porque a política fiscal é particularmente procíclica durante estes períodos, ou seja, as autoridades podem desejar implementar políticas contracíclicas, mas são impedidas devido a impossibilidade de financiar os déficits fiscais associados a este tipo de política. 


\subsection{Barreiras Institucionais}

A existência de regras para o equilíbrio orçamentário do governo, impostas constitucionalmente, pode limitar a habilidade dos governos de tomarem empréstimos, impedindo-os de recorrerem a tal financiamento durante períodos recessivos (Sorensen e Yosha, 2001). Logo, a capacidade de resposta fiscal durante episódios de desaceleração econômica fica restringida pela quantidade poupada durante episódios de expansão.

Alesina e Bayoumi (1996) observam que existem duas questões críticas em relação ao uso de regras para o equilíbrio do orçamento do governo. A primeira é saber se estas regras são efetivas no sentido de forçar uma disciplina fiscal, e a segunda diz respeito aos seus beneficios (em termos de disciplina fiscal) e malefícios (em termos de volatilidade do produto). Uma menor flexibilidade orçamentária deveria ter custos em termos de volatilidade do produto tanto em uma abordagem neoclássica, pois limita a habilidade do governo de suavizar os impostos ao longo do tempo, quanto em uma abordagem keynesiana, devido a necessidade de adotar políticas contracíclicas. ${ }^{6}$

\subsection{O Ciclo Político}

Uma possível fonte geradora de assimetrias na política fiscal está ligada à questão política, sendo que esta pode ser subdividida em "ciclos eleitorais", "voracidade política", e "fragmentação política".?

A idéia básica do ciclo político é a de que os governos seguem políticas expansionistas durante anos eleitorais com o intuito de se manterem no poder (Mayr e Scharler, 2009). Se este comportamento for mais atraente durante períodos de aceleração cria-se uma possível assimetria fiscal.

A questão da voracidade política foi apresentada por Tornell e Lane (1999), através do desenvolvimento de um modelo teórico onde grupos políticos influentes disputam parcelas dos recursos fiscais para direcioná-los aos seus eleitores (tal característica é chamada de voracidade política). Com isso os governos passam a temer que os superávits sejam gastos por grupos políticos vorazes e, assim, acabam por não acumular recursos durante períodos econômicos mais favoráveis e que poderiam ser utilizados para manter os gastos durantes as recessões (Sorensen e Yosha, 2001).

Ainda em relação às fontes políticas de assimetria fiscal, pode-se citar a fragmentação eleitoral. Mayr e Scharler (2009) observam que a proporcionalidade eleitoral pode levar a maiores déficits fiscais, uma vez que em governos mais fragmentados (ou seja, onde existe um maior número de partidos políticos) há um maior número de grupos de interesse disputando os recursos públicos.

\section{METODOLOGIA}

Para investigar o comportamento da política fiscal brasileira ao longo do ciclo econômico e verificar se a mesma apresenta assimetrias é necessário que se introduza a possibilidade da existência de não linearidades na modelagem econométrica. Para tanto foi utilizado a metodologia da Autorregressão Vetorial com Mudanças Markovianas (MS-VAR) ${ }^{8}$ onde a função de impulso-resposta depende do regime no qual a economia se encontra.

A assimetria, aqui considerada, está relacionada à questão da direção, da velocidade e da dimensão das respostas fiscais. Dessa forma, ocorre assimetria na direção da política quando o governo adota políticas procíclicas durante uma fase do ciclo e políticas contracíclicas em outra fase. Já a assimetria

\footnotetext{
${ }^{6}$ Analisando a economia norte-americana, Alesina e Bayoumi (1996) concluíram que as regras fiscais foram efetivas no sentido de assegurar a disciplina orçamentária e não trouxeram custos em termos de variabilidade do produto.

${ }^{7}$ É importante ressaltar que existem outras fontes políticas para a assimetria da política monetária, mas a completa caracterização dessas está fora do escopo desta pesquisa.

${ }^{8}$ Do inglês Markov Switching Vector Autoregression.
} 
na velocidade é verificada quando a autoridade adota medidas fiscais de forma mais ágil em uma determinada fase do ciclo. Por fim, ocorre assimetria na dimensão da política fiscal quando o tamanho da reação do governo varia de acordo com a fase do ciclo.

\subsection{Modelos com Mudanças de Regime Markovianos}

Uma cadeia markoviana é um processo estocástico representado por sistema de transições de estados onde as distribuições de probabilidade para o seu desempenho no futuro dependem somente do estado presente. Ou seja, a probabilidade de se estar em um determinado estado no futuro pode depender do estado atual do sistema, mas não depende do estado passado. Imagine um sistema ao qual num determinado instante de tempo se encontre no estado dentre os estados possíveis. O sistema pode evoluir, a intervalos de tempo regulares, para outro estado ou permanecer onde se encontra. Isso ocorre em função de uma probabilidade de transição entre estados.

A probabilidade de transição de um estado para outro é definida como $P_{i j}$, que indica a probabilidade de passar de um estado $i$ no momento atual para um estado $j$ no intervalo de tempo seguinte. Representando a cadeia de Markov como uma matriz de transição $P=\left[P_{i j}\right]_{N x N}$ onde a probabilidade de transição do estado $i$ para o estado $j$ em dois períodos de tempo é dada por:

$$
P_{i j}^{(2)}=P_{i 1} \cdot P_{1 j}+P_{i 2} \cdot P_{2 j}+\ldots+P_{i N} \cdot P_{N j}
$$

Assim, considerando que o estado inicial do sistema seja $i$, a probabilidade do sistema se encontrar no estado $j$ no tempo $n$ é $P_{i j}^{(n)}$. Supondo que para cada $n \geq 0, \pi_{j}^{(n)}$ seja a probabilidade de uma cadeia de Markov estar no estado $j$ e no tempo $n$ então se a cadeia de Markov tiver $N$ estados, $1,2, \ldots, N$, podemos escrever um vetor $\pi^{(n)}$ de distribuição da cadeia de Markov no tempo $n$. Assim, a distribuição da cadeia de Markov a qualquer tempo é dada por:

$$
\pi^{(n)}=\pi^{(0)} \cdot P^{n}
$$

(2) onde $\pi^{(0)}$ é a distribuição inicial da cadeia. Uma característica importante da cadeia de Markov é que esta apresenta um comportamento de equilíbrio de longo prazo, ou seja, após um longo tempo a distribuição da cadeia permanece praticamente inalterada.

Os modelos autorregressivos com mudanças markovianas podem ser considerados uma generalização dos modelos VAR. Assumindo um vetor com $K$ séries de tempo, $y_{t}=\left(y_{1 t}, \ldots, y_{k t}\right)^{\prime}$ observado no período $t=1, \ldots, T$, o modelo MS-VAR pode ser descrito como:

$$
y_{t}=v\left(s_{t}\right)+A_{1}\left(s_{t}\right) y_{t-1}+\ldots+A_{p}\left(s_{t}\right) y_{t-p}+u_{t}
$$

(3) onde $u_{t} \mid s_{t} N I D\left(0, \sum\left(s_{t}\right)\right)$.

Um modelo MS(N)-VAR(p) é um modelo VAR de ordem $p$ e com $N$ estados possíveis, onde as funções $v\left(s_{t}\right) A_{1}\left(s_{t}\right), \ldots, A_{p}\left(s_{t}\right)$ e $\sum\left(s_{t}\right)$ descrevem a dependência dos parâmetros do modelo em relação à variável de regime. Logo, os parâmetros são variantes no tempo, porém considerados constantes quando condicionados a $s_{t} \in\{1, \ldots, N\}$. Assim, no caso do parâmetro $v\left(s_{t}\right)$, tem-se que:

$$
v\left(s_{t}\right)=\left\{\begin{array}{c}
v_{t}=\left(v_{11}, \ldots, v_{k 1}\right)^{\prime}, \text { se } s_{t}=1 \\
\vdots \\
v_{N}=\left(v_{1 N}, \ldots, v_{k N}\right)^{\prime}, \text { se } s_{t}=N
\end{array}\right.
$$

O modelo MS-VAR fornece um aparato flexível que permite verificar as mudanças na tendência, nos parâmetros autorregressivos e/ou na variância dos resíduos ao longo do tempo.

Para a realização da estimação dos parâmetros de modelos markovianos a maximização da função logaritmo da verossimilhança (MLE) é usualmente utilizada. Porém, como a variável de regime é 
governada por uma cadeia de Markov, o modelo passa a ter características não lineares, o número de parâmetros a serem estimados aumenta significativamente e a estimação através do processo MLE pode oferecer estimativas não confiáveis. Alternativamente ao processo MLE, a utilização do algoritmo EM (Expectation-Maxization) torna possível a estimação dos parâmetros do MS-VAR.

\subsection{Dados}

Para a realização da modelagem econométrica desse artigo utilizou-se as variáveis com periodicidades mensais e compreendidas entre janeiro de 2001 e dezembro de 2010 . As séries foram deflacionadas, onde necessário, pelo IPCA e passaram por ajustes de sazonalidade (via método X-12-Arima), sendo obtidas através do Sistema Gerenciador de Séries Temporais do Banco Central do Brasil (BACEN).

Produto doméstico $(y)$ : foi utilizado o produto interno bruto mensal calculado pelo Banco Central (código BACEN: 4380). Cabe ressaltar que o PIB mensal é resultado de estimações realizadas pelo Banco Central, sendo, portanto, sujeito a erros estatísticos e atualizações regulares. Para o cálculo do hiato do produto $(h)$ utilizou-se o PIB potencial $(\bar{y})$ obtido via filtro de Hodrick-Prescott, assim, algebricamente, tem-se: $h=\ln \left(\frac{y}{\bar{y}}\right)$.

Superávit primário $(B)$ : representado pelo resultado primário do governo central, conforme divulgado pela Secretaria do Tesouro Nacional (código BACEN: 7557).

Gastos do governo $(G)$ : equivale a despesa total do governo federal, conforme divulgado pela Secretaria do Tesouro Nacional (código BACEN: 7547).

Receita do governo $(T)$ : consiste na receita total do governo federal, conforme divulgado pela Secretaria do Tesouro Nacional (código BACEN: 7544).

Taxa de juros domésticos $(i)$ : representada pela taxa Over-Selic acumulada no mês anualizada, divulgada pelo Banco Central (código BACEN: 4189).

Inflação $(\pi)$ : representada pelo índice nacional de preços ao consumidor amplo (IPCA), medido em variação mensal e calculado pelo Instituto Brasileiro de Geografia e Estatística (código BACEN: 433).

O Apêndice A apresenta as metodologias utilizadas para identificar os componentes cíclicos e discricionários da política fiscal.

\subsection{Análise Descritiva}

Antes da análise econométrica formal da não linearidade fiscal, foi realizada uma análise descritiva preliminar com o intuito de averiguar a possibilidade de existência de assimetrias.

O primeiro passo para a identificação das assimetrias consistiu na definição de aceleração e desaceleração econômica. Neste artigo, períodos de desaceleração (ou aceleração) econômica foram definidos como sendo períodos onde o hiato do produto observado foi menor (ou maior) que 0,5 desvio padrão. ${ }^{9} \mathrm{~A}$ Figura 1 mostra a dinâmica do hiato do produto ao longo do tempo, com as áreas sombreadas indicando os períodos de desaceleração e crescimento.

Esse critério de classificação do ciclo identificou quatro períodos com aceleração e três com desaceleração, conforme apresenta a Figura 1. Uma análise descritiva foi feita para analisar o comportamento da política fiscal durante tais episódios, comparando-o com o comportamento da política monetária. As Tabelas 1 e 2 sumarizam os resultados dessa análise.

\footnotetext{
${ }^{9}$ Os períodos identificados, apresentados na Figura 1, diferem dos definidos pelo Comitê de Datação de Ciclos Econômicos da Fundação Getúlio Vargas (Codace/FGV). Isso ocorre pois o hiato calculado neste ensaio teve como base o PIB mensal acumulado em 12 meses, dessa forma, para evitar problemas de compatibilidade dos dados optou-se por uma datação própria.
} 
Figura 1: Períodos de Aceleração e Desaceleração
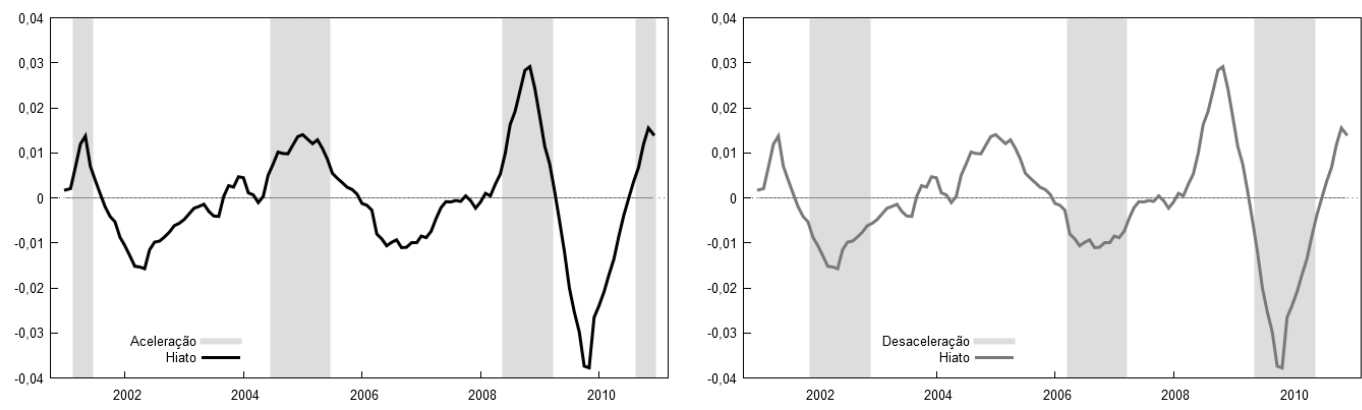

Nota: Gráficos via programa Gretl (versão 1.9.7).

Tabela 1: Velocidade e Frequência do Estímulo Fiscal Durante Desacelerações - Dados Mensais (2000:1 - 2009:12)

\begin{tabular}{|c|c|c|c|c|c|}
\hline & OCDE & FMI (2006) & Holandês & FMI (2008) & Kalman \\
\hline \multicolumn{6}{|l|}{ Velocidade da resposta } \\
\hline Política fiscal discricionária & 0,33 & 0,33 & 1,33 & 0,33 & 0,33 \\
\hline Política fiscal cíclica & 0,00 & 0,00 & 0,00 & 0,00 & 1,33 \\
\hline Política monetária & 0,67 & 0,67 & 0,67 & 0,67 & 0,67 \\
\hline \multicolumn{6}{|l|}{ Frequência da resposta } \\
\hline Política fiscal discricionária (\%) & 61,1 & 58,3 & 52,8 & 50,0 & 52,8 \\
\hline Política fiscal cíclica (\%) & 47,2 & 50,0 & 52,8 & 58,3 & 38,9 \\
\hline Política monetária (\%) & 55,6 & 55,6 & 55,6 & 55,6 & 55,6 \\
\hline Episódios de desaceleração & 3 & & & & \\
\hline Duração média das desacelerações & 12 & & & & \\
\hline Número de meses com desaceleração & 36 & & & & \\
\hline Quantidade de meses na amostra & 119 & & & & \\
\hline Percentual de meses com desaceleração (\%) & 30,3 & & & & \\
\hline
\end{tabular}

A Tabela 1 apresenta o comportamento das políticas fiscal e monetária durante os períodos de desaceleração econômica. Ela indica que tais períodos ocorreram em cerca de 30,3\% da amostra.

Estímulos fiscais discricionários ocorrem em aproximadamente 60,0\% dos meses de recessão quando consideradas as metodologias da OCDE e do FMI (2006). Essa razão caiu para algo em torno de 50,0\% no método Holandês, na metodologia do FMI (2008) e no filtro de Kalman. O Apêndice A apresenta os cálculos utilizados para obter os componentes da política fiscal em cada um desses métodos.

A política fiscal cíclica esteve presente em $47,2 \%$ da amostra quando considerado a metodologia da OCDE, 50,0\% pela metodologia FMI (2006), 52,8\% pelo método Holandês, 58,3\% pelo método FMI (2008) e $38,9 \%$ pelo filtro de Kalman. Esses resultados indicam que apenas com base na metodologia do FMI (2008) os estabilizadores automáticos são utilizados de forma mais frequente que a políticas discricionárias. Essa conclusão pode parecer um tanto quanto inconsistente, uma vez que pela própria definição, o componente cíclico da política fiscal deveria agir de forma automática em resposta à variações no pro- 
duto. Porém, no caso em questão, a desaceleração é definida como sendo um período onde o produto está abaixo do seu potencial, o que pode ocorrer mesmo em um ambiente de crescimento positivo.

Em relação ao tempo que se leva para a implementação da política, vê-se que, através das metodologias OCDE, FMI (2006), FMI (2008) e filtro de Kalman, o estímulo fiscal discricionário foi adotado menos de um mês após o início da recessão (mais especificamente, esse tipo de política foi adotada após 0,33 mês). Através do método Holandês, a implementação da política fiscal discricionária ocorreu após 1,33 mês.

A política fiscal cíclica, por sua vez, é imediatamente acionada (ou seja, 0 mês) no período de recessão, com exceção da metodologia via filtro de Kalman onde se espera 1,33 mês para sua implementação. Esses resultados ajudam a corroborar a idéia de que a regra fiscal age de forma mecânica em relação ao ciclo.

A política monetária contracíclica é implementada, em média, após 0,67 mês. Com isso, tem-se que o Banco Central reage mais lentamente que a autoridade fiscal diante de episódios de desaceleração. Tal comportamento se inverte nos períodos de aceleração, o que pode ser verificado na Tabela 2 a seguir.

Tabela 2: Velocidade e Frequência do Estímulo Fiscal Durante Acelerações - Dados Mensais (2000:1 - 2009:12)

\begin{tabular}{lccccc}
\hline & OCDE & FMI (2006) & Holandês & FMI (2008) & Kalman \\
\hline Velocidade da resposta & & & & & \\
$\quad$ Política fiscal discricionária & 0,75 & 2,00 & 2,25 & 0,25 & 1,50 \\
$\quad$ Política fiscal cíclica & 0,00 & 0,00 & 0,25 & 0,50 & 0,25 \\
$\quad$ Política monetária & 0,25 & 0,25 & 0,25 & 0,25 & 0,25 \\
Frequência da resposta & & & & 50,0 & 40,0 \\
$\quad$ Política fiscal discricionária (\%) & 53,3 & 46,7 & 40,0 & 60,0 & 60,0 \\
$\quad$ Política fiscal cíclica (\%) & 60,0 & 60,0 & 63,3 & 70,0 \\
$\quad$ Política monetária (\%) & 70,0 & 70,0 & 70,0 & & 70,0 \\
\hline Episódios de aceleração & 4 & & & & \\
Duração média das acelerações & 7,5 & & & & \\
Número de meses com aceleração & 30 & & & & \\
Quantidade de meses na amostra & 119 & & & & \\
Percentual de meses com aceleração (\%) & 25,2 & & & & \\
\hline
\end{tabular}

Notas: (1) Elaboração própria com dados da pesquisa, com base em Leigh e Stehn (2009);

(2) Velocidade da resposta diz respeito a quantidade média de meses que se passou até que

a autoridade fiscal/monetária tenha adotado uma política contracíclica.

A Tabela 2 mostra que episódios de aceleração foram verificados em quatro ocasiões dentro da amostra, o que representam $25,2 \%$ do total de meses. Nesse caso, a política discricionária age de forma menos frequente que a cíclica em todas as metodologias. Essa conclusão é bastante interessante, uma vez que fornece um forte indício de que o governo age de forma discricionária com maior frequência nos momentos onde a atividade econômica apresenta desempenho mais modesto.

Resultado também importante é o fato da política fiscal cíclica e da política monetária serem mais frequentemente utilizadas durante as acelerações. Assim, durante períodos de melhor desempenho da economia a autoridade fiscal age menos discricionariamente que nos períodos de desaceleração. Esse comportamento pode sugerir que o governo eleve seus gastos líquidos durante as desacelerações mas não os reduz na mesma proporção nas acelerações. Ou seja, o governo aparentemente se preocupa mais com as reduções do produto.

Já o Banco Central age mais ativamente quando a economia encontra-se aquecida. Esse comportamento pode ser um reflexo da maior preocupação da autoridade monetária com a pressão inflacionária que surge em um ambiente de maior atividade econômica. 
Em relação à velocidade de resposta, tem-se que a política monetária age 0,25 mês após o início do ciclo de aceleração. Ou seja, no geral, a política monetária age de forma mais rápida que a fiscal, com exceção apenas para a política fiscal cíclica calculada via OCDE e via FMI (2006) que atuam imediatamente (período zero).

Comparando os dois componentes fiscais, percebe-se que a política fiscal cíclica age de forma predominantemente mais rápida que a discricionária. Esse é mais um ponto a confirmar o caráter automático da regra fiscal.

Por fim, as políticas, ao responderem com diferentes frequências e prazos nos dois cenários distintos, fornecem um indício importante de não linearidade nas respostas fiscais e monetárias do governo.

\subsection{Estimações}

As estimações foram realizadas de forma a permitir a presença de não linearidades. Para tanto, foram adotados modelos autorregressivos com mudanças markovianas capazes de lidar com a questão das relações assimétricas entre as variáveis. Entre as várias classes de modelo MS-VAR, ${ }^{10}$ escolheu-se o modelo MSMH-VAR, onde a média e as variâncias das variáveis apresentam diferenças entre os regimes.

A Tabela 3 mostra o resultado dos testes de Akaike (AIC), Hannan-Quinn (HQC) e Schwarz (SBC) para escolha do número ótimo de defasagem do MS-VAR. Todos os três critérios indicaram que a modelagem com apenas uma defasagem seria a mais indicada, porém, na estimação dos modelos tradicional, OCDE, FMI (2006), FMI (2008) utilizou-se duas defasagens para correção de problemas como autocorrelação e heteroscedasticidade.

Apesar das análises preliminares indicarem a presença de relações assimétricas entre as variáveis em questão, realizou-se um teste mais formal para confirmar a não linearidade nas respostas fiscais e monetárias. O teste de razão de verossimilhança (teste LR) apresentado na Tabela 4 apontou que a modelagem com mudança de regime é a mais adequada, pois a hipótese nula de linearidade foi rejeitada, com exceção da metodologia do FMI (2008). ${ }^{11}$ Tal resultado pode justificar a utilização do modelo MS$\mathrm{VAR}^{12}$

Conforme discutido anteriormente isso pode acontecer pelo fato dos formuladores de políticas reagirem, de forma assimétrica, à períodos de recessão e expansão econômica, no sentindo de promoverem políticas de afrouxamento em períodos de recessão e não adotarem políticas suficientemente restritivas em períodos de crescimento.

O número de regimes foi fixado em 2 e podem ser interpretados como sendo períodos de crescimento e de recessão na economia. A Tabela 5 apresenta as matrizes de transição dos MS-VARs estimados para cada tipo de metodologia.

Em geral, os regimes estimados se mostraram bastante persistentes, ou seja, estando no regime 1 ou 2, a probabilidade de mudança de regime é consideravelmente menor do que a probabilidade de permanência no regime em que se encontra. Através da metodologia da OCDE, por exemplo, pode-se observar que encontrando-se no regime 1, a probabilidade de permanência no mesmo é de $96,62 \%$, enquanto que a probabilidade de mudança para o regime 2 é de 13,48\%. E, encontrando-se no regime 2, a probabilidade de permanência no mesmo é de $86,52 \%$ e a de mudança para o regime 1 é de 3,38\%.

A Figura 2 apresenta as probabilidades estimadas da economia se encontrar em determinado regime. A análise das figuras mostra que, independentemente da metodologia de decomposição da política fiscal utilizada (OCDE, FMI (2006), Método Holandês, FMI (2008) e Filtro de Kalman), os períodos pertencentes ao regime 2 são, de acordo com o critério utilizado neste artigo, períodos onde o produto ficou conside-

\footnotetext{
${ }^{10}$ Para uma apresentação mais completa das diferentes classes de modelos markovianos ver Krolzig (1998).

${ }^{11}$ Apesar do teste LR aceitar a hipótese de linearidade no modelo baseado na metodologia FMI (2008), o mesmo foi mantido nas análises posteriores para fins ilustrativos.

${ }^{12}$ As séries foram submetidas a vários testes de estacionariedade e de cointegração.
} 
Tabela 3: Testes para Escolha do Número de Defasagens

\begin{tabular}{|c|c|c|c|c|c|c|}
\hline & defasagem $=1$ & defasagem $=2$ & defasagem $=3$ & defasagem $=4$ & defasagem $=5$ & defasagem $=6$ \\
\hline \multicolumn{7}{|c|}{ Tradicional } \\
\hline AIC & $-9,7850^{*}$ & $-9,5685$ & $-9,3765$ & $-9,5171$ & $-9,4158$ & $-9,2108$ \\
\hline HQC & $-9,3344^{*}$ & $-8,9612$ & $-8,6125$ & $-8,5965$ & $-8,3385$ & $-7,9768$ \\
\hline $\mathrm{SBC}$ & $-8,6747^{*}$ & $-8,0720$ & $-7,4938$ & $-7,2483$ & $-6,7609$ & $-6,1697$ \\
\hline \multicolumn{7}{|l|}{ OCDE } \\
\hline AIC & $-19,8094^{*}$ & $-19,1937$ & $-18,8437$ & n.d. & $-18,9326$ & $-18,1416$ \\
\hline HQC & $-19,1532^{*}$ & $-18,2927$ & $-17,6978$ & n.d. & $-17,2970$ & $-16,2611$ \\
\hline $\mathrm{SBC}$ & $-18,1923^{*}$ & $-16,9732$ & $-16,0198$ & n.d. & $-14,9019$ & $-13,5074$ \\
\hline \multicolumn{7}{|c|}{ FMI (2006) } \\
\hline AIC & $-22,0378^{*}$ & $-21,0046$ & $-20,8049$ & $-20,8472$ & $-21,0497$ & $-20,2899$ \\
\hline HQC & $-21,3815^{*}$ & $-20,1036$ & $-19,6590$ & $-19,4564$ & $-19,4140$ & $-18,4094$ \\
\hline $\mathrm{SBC}$ & $-20,4206^{*}$ & $-18,7841$ & $-17,9810$ & $-17,4198$ & $-17,0189$ & $-15,6557$ \\
\hline \multicolumn{7}{|l|}{ Holandês } \\
\hline AIC & $-18,3499^{*}$ & $-11,8594$ & $-16,8554$ & $-10,8323$ & $-17,1656$ & $-16,4320$ \\
\hline HQC & $-17,6937^{*}$ & $-10,9583$ & $-15,7094$ & $-9,4415$ & $-15,5299$ & $-14,5516$ \\
\hline $\mathrm{SBC}$ & $-16,7328^{*}$ & $-9,63890$ & $-14,0314$ & $-7,4049$ & $-13,1348$ & $-11,7979$ \\
\hline \multicolumn{7}{|c|}{ FMI (2008) } \\
\hline AIC & $-16,5065^{*}$ & $-12,1994$ & $-16,3524$ & $-10,3592$ & n.d. & n.d. \\
\hline HQC & $-15,8503^{*}$ & $-11,2983$ & $-15,2065$ & $-8,9684$ & n.d. & n.d. \\
\hline SBC & $-14,8894^{*}$ & $-9,9789$ & $-13,5285$ & $-6,9319$ & n.d. & n.d. \\
\hline \multicolumn{7}{|l|}{ Kalman } \\
\hline AIC & $-15,6789$ & $-13,7140$ & $-13,6958$ & $-13,8606$ & n.d. & n.d. \\
\hline HQC & $-15,0436$ & $-12,8369$ & $-12,5744$ & $-12,4923$ & n.d & n.d. \\
\hline $\mathrm{SBC}$ & $-14,1142$ & $-11,5538$ & $-10,9336$ & $-10,4899$ & n.d. & n.d. \\
\hline
\end{tabular}

Notas: (1) Os asteriscos indicam os melhores (isto é, minimizados) valores dos respectivos critérios de informação;

(2) AIC representa o critério de Akaike, SBC representa o critério bayesiano de Schwarz e HQC representa o critério de Hannan-Quinn;

(3) Não foi possível calcular as estatísticas na metodologia da OCDE e do FMI (2008), isso ocorreu devido a falta de convergência desses modelos com determinadas defasagens;

(4) Resultados obtidos via pacote MSVAR (versão 1.32a) para Ox (versão 3.00).

ravelmente abaixo de seu potencial. Assim sendo, o regime 2 foi chamado de período de desaceleração e o regime 1 de aceleração.

As Figuras 3 e 4 mostram as respostas das variáveis fiscais e monetárias a choques negativos de uma unidade na variação do hiato do produto. É importante levar em consideração que, diferentemente da modelagem linear, aqui as funções de impulso-resposta dependem do regime no qual a economia se encontra. ${ }^{13}$

As variáveis foram ordenadas no VAR da seguinte forma: hiato, inflação, juros, impulso e regra fiscal. Assim, a variação do hiato do produto não reage contemporaneamente a choques de outras variáveis do sistema; a inflação é afetada por choques na variação do hiato do produto instantaneamente; a taxa de juros é afetada simultaneamente por choques na variação do hiato do produto e inflação; as variáveis fiscais são afetadas no mesmo instante dos choques iniciais em todas as variáveis do sistema.

Conforme mostra a Figura 3, a política fiscal é contracíclica tanto em períodos de recessão quanto de crescimento. Já a política monetária se mostra contracíclica no regime de crescimento e inicialmente

\footnotetext{
${ }^{13} \mathrm{~A}$ introdução de funções impulso-resposta na análise de modelos MS-VAR foi realizada por Ehrmann et alii (2003).
} 
Figura 2: Probabilidades Estimadas
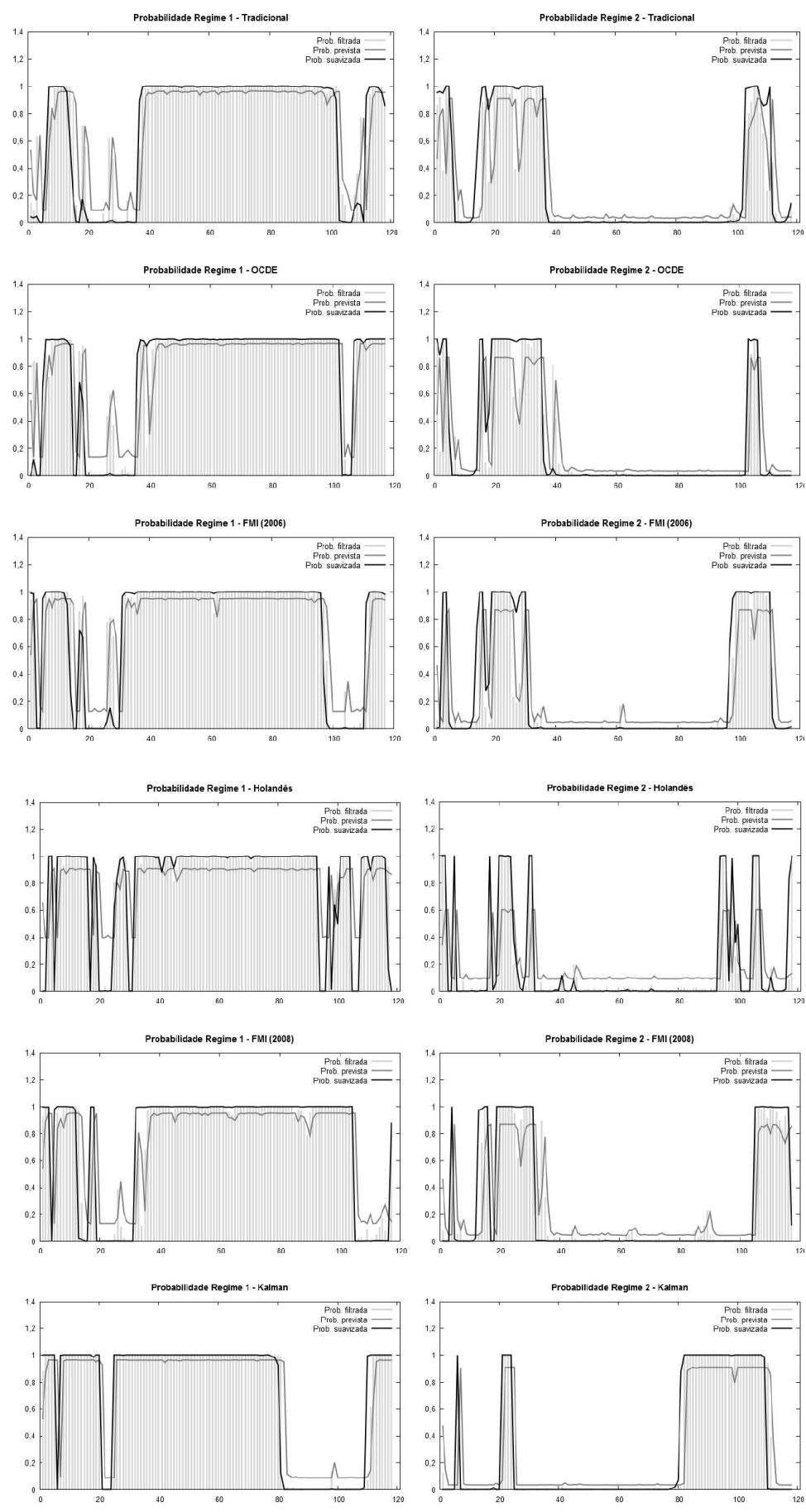

Notas: (1) Elaboração própria com dados da pesquisa; (2) Resultados obtidos via pacote MSVAR (versão 1.32a) para Ox (versão 3.00); (3) Gráficos obtidos via Gretl (versão 1.9.7). 
Tabela 4: Testes LR de Linearidade

\begin{tabular}{lcccc}
\hline & Estatística LR & Chi $(20)$ & Chi $(22)$ & Davies \\
\hline Tradicional & 109,6535 & {$[0,0000]^{* *}$} & {$[0,0000]^{* *}$} & {$[0,0000]^{* *}$} \\
OCDE & 135,4841 & {$[0,0000]^{* *}$} & {$[0,0000]^{* *}$} & {$[0,0000]^{* *}$} \\
FMI (2006) & 146,7174 & {$[0,0000]^{* *}$} & {$[0,0000]^{* *}$} & {$[0,0000]^{* *}$} \\
Holandês & 152,8605 & {$[0,0000]^{* *}$} & {$[0,0000]^{* *}$} & {$[0,0000]^{* *}$} \\
FMI (2008) & $-204,3301$ & {$[1,0000]$} & {$[1,0000]$} & n.d. \\
Kalman & 256,2910 & {$[0,0000]^{* *}$} & {$[0,0000]^{* *}$} & {$[0,0000]^{* *}$} \\
\hline
\end{tabular}

Notas: (1) A hipótese nula é de linearidade do modelo;

(2) Resultados obtidos via pacote MSVAR (versão 1.32a) para Ox (versão 3.00).

Tabela 5: Matriz de Probabilidades

\begin{tabular}{lcccc}
\hline & $\mathrm{P}\left(s_{t+1}=1 \mid s_{t}=1\right)$ & $\mathrm{P}\left(s_{t+1}=2 \mid s_{t}=1\right)$ & $\mathrm{P}\left(s_{t+1}=1 \mid s_{t}=2\right)$ & $\mathrm{P}\left(s_{t+1}=2 \mid s_{t}=2\right)$ \\
\hline Tradicional & 0.9673 & 0,0915 & 0,0327 & 0.9085 \\
OCDE & 0,9662 & 0,1348 & 0,0338 & 0,8652 \\
FMI (2006) & 0,9538 & 0,1280 & 0,0462 & 0,8720 \\
Holandês & 0,9090 & 0,3965 & 0,0910 & 0,6035 \\
FMI (2008) & 0,9538 & 0,1298 & 0,0462 & 0,8702 \\
Kalman & 0,9645 & 0,0888 & 0,0355 & 0,9112 \\
\hline
\end{tabular}

Notas: (1) $\mathrm{P}(\mathrm{st}+1=\mathrm{j} \mid \mathrm{st}=\mathrm{i})$ indica a probabilidade da cadeia passar para o regime $j$ dado que ela está no regime $i$;

(2) Resultados obtidos via pacote MSVAR (versão 1.32a) para Ox (versão 3.00).

procíclica no regime de recessão, tornando-se contracíclica a partir do segundo período após o choque. Assim, pode-se concluir que a política fiscal é mais ágil do que a política monetária quando a primeira não é decomposta em regra e discrição.

Com base na metodologia da OCDE, tanto o impulso fiscal quanto a regra são contracíclicas nos dois regimes. Já a política monetária reage de maneira distinta nos dois regimes, se mostrando contracíclica no regime 1 e, inicialmente, procíclica no regime 2. Porém, a política monetária passa a se comportar contraciclicamente a partir do segundo período após o choque.

O modelo FMI (2006) mostra que a política fiscal se comporta de forma semelhante nos dois regimes, agindo de forma contracíclica apenas a partir do terceiro momento após a redução do hiato. Em relação à política monetária observa-se que esta responde mais rapidamente que o impulso fiscal, sendo adotada no mesmo período em que ocorre o choque quando a economia se encontra no regime de aceleração e um período após o choque quando a economia encontra-se no regime de desaceleração. A política de regra age instantaneamente e de forma contracíclica.

No método Holandês o impulso fiscal responde prociclicamente ao choque no hiato, enquanto a regra responde de forma contracíclica. A regra fiscal, mais uma vez, se mostra mais ágil que o impulso. A política monetária é contracíclica durante o regime 2 e comporta-se dessa mesma forma apenas no 
Figura 3: Probabilidades Estimadas

Choques negativos de 1 unidade na variação do hiato do produto

Resposta do balanço fiscal a um choque de 1 unidade no hiato

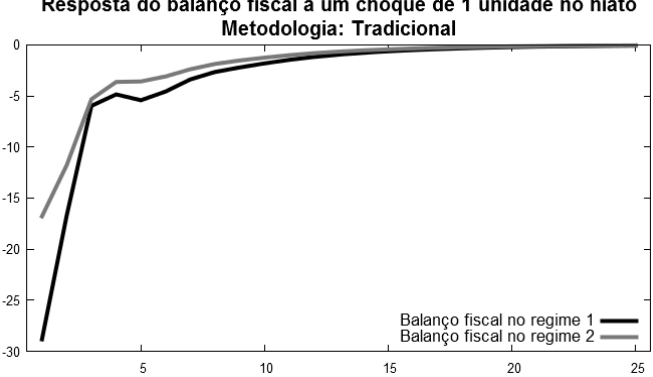

Resposta dos juros a um choque de 1 unidade no hiato

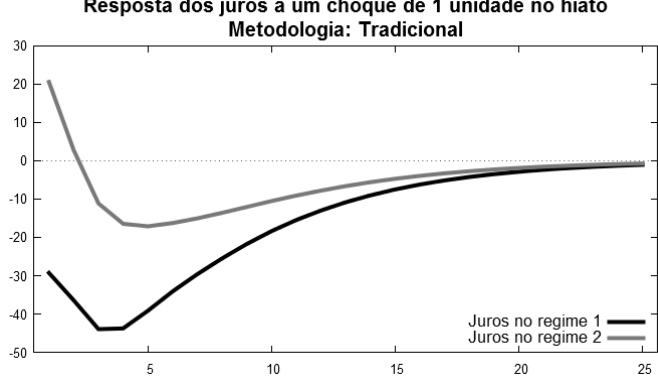

Nota: Cálculos realizados via programa Gretl (versão 1.9.7).

momento seguinte ao choque no hiato durante o regime 1 , resultado oposto ao encontrado através das metodologias da OCDE, FMI(2006) e FMI (2008).

O modelo FMI (2008) demonstra um resultado particular uma vez que o impulso fiscal é considerado, no momento inicial do impacto, contracíclico no regime 1 e procíclico no regime 2 . A regra, num primeiro momento é contracíclica nos dois regimes. A política monetária segue uma trajetória similar a encontrada através dos modelos OCDE e FMI (2006).

A estimação via filtro de Kalman mostra uma política fiscal procíclica no regime 1 e contracíclica no regime 2. Resultado oposto ao modelo FMI (2008). A regra fiscal apresenta-se oportuna e ágil em ambos os regimes. Analisando a política monetária, nota-se que os resultados se assemelham ao método Holandês, ou seja, durante o regime 2 a política fiscal é contracíclica, já no regime 1, ela é inicialmente procíclica até que sua trajetória converte para a mesma trajetória do regime 2.

Em linhas gerais, as funções de impulso-resposta estimadas mostram que, em três dos cinco métodos (FMI (2006), Holandês e Kalman), a discrição fiscal age de forma procíclica durante o regime de aceleração econômica. Esse resultado é compatível com outros estudos que concluíram que, principalmente nos países em desenvolvimento da América Latina, a autoridade fiscal comporta-se prociclicamente durante as acelerações econômicas. Enquanto isso, a política monetária comporta-se de forma predominantemente contracíclica. Em relação à política regra, conclui-se que a mesma possui o maior grau de simetria. 
Figura 4: Probabilidades Estimadas

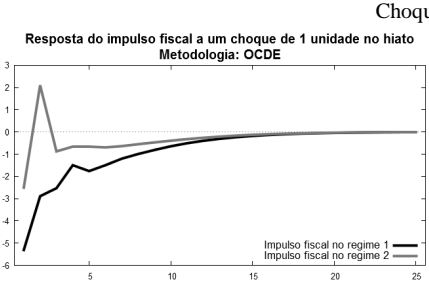

Choques negativos de 1 unidade na variação do hiato do produto
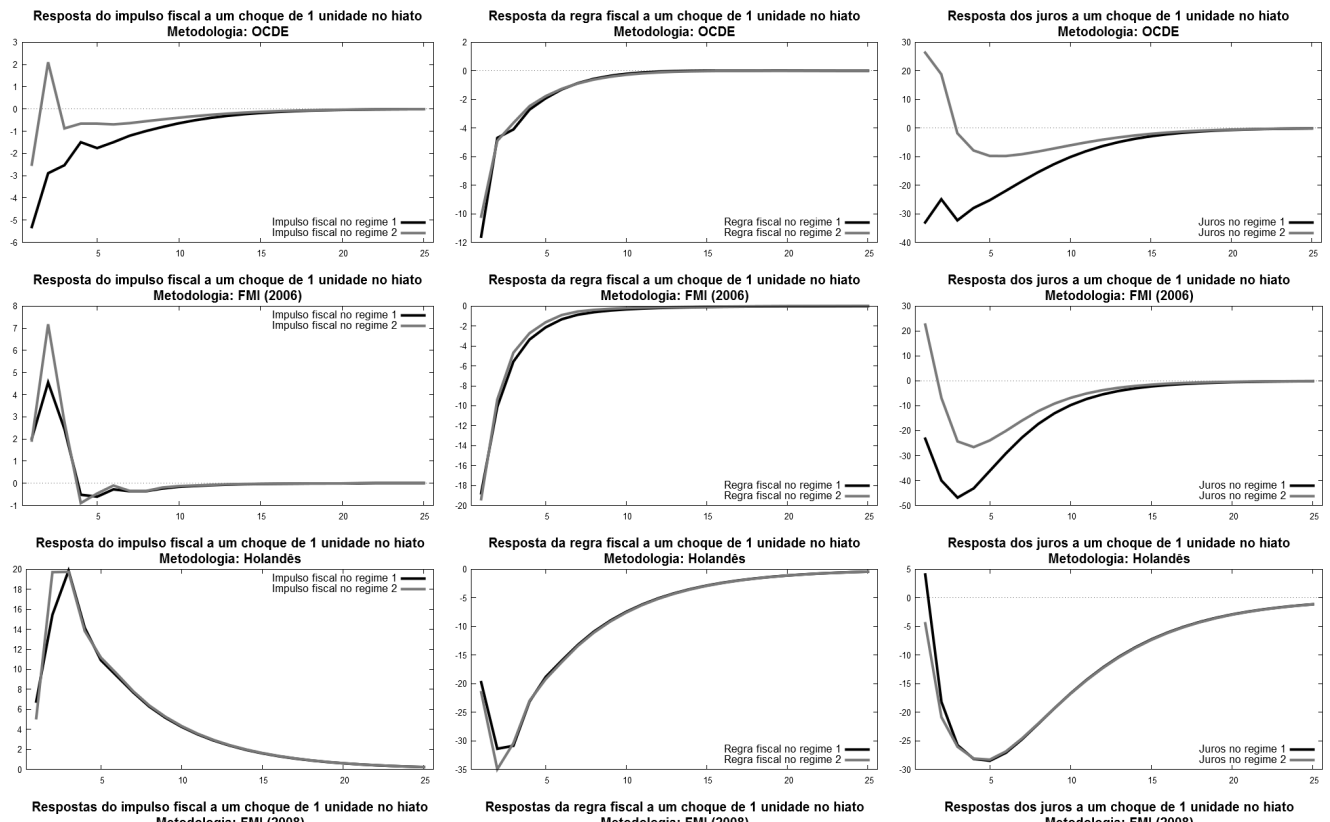

Resposta dos juros a um choque de 1 unidade no hiato

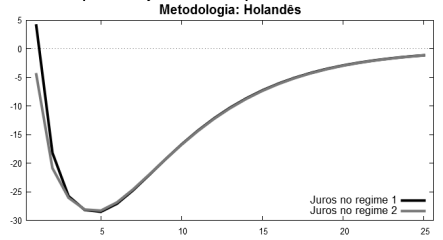

Respostas da regra fiscal a um choque de 1 unidade no hiato
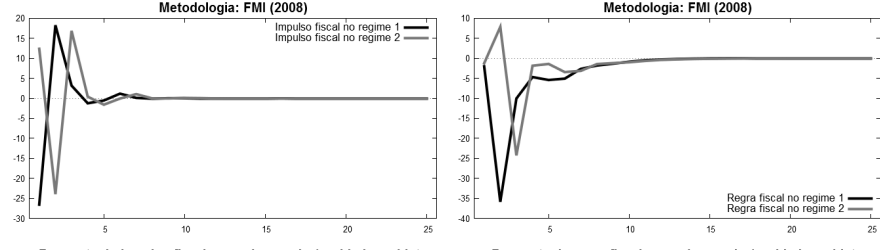

Respostas dos juros a um choque de 1 unidade no hiato

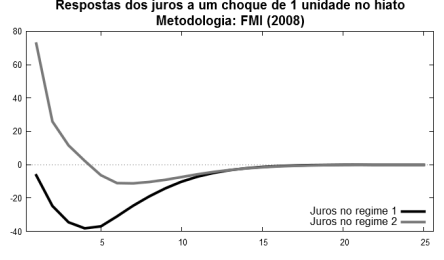

Resposta da regra fiscal a um choque de 1 unidade no hiato
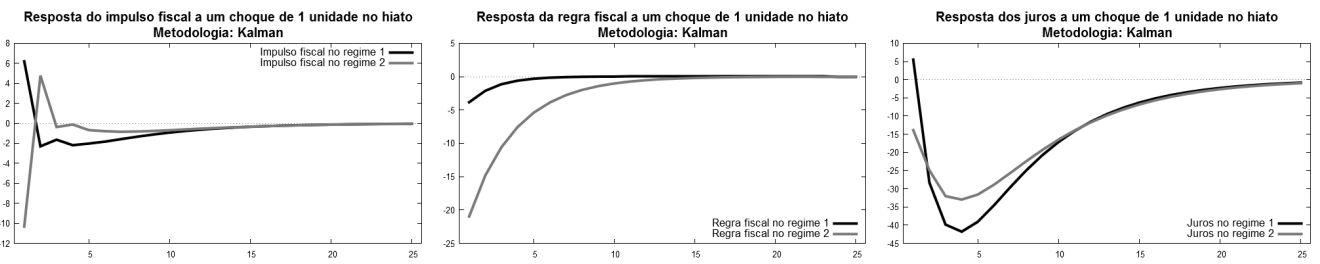

Notas: (1) Cálculos realizados via pacote MSVAR (versão 1.32a) para Ox (versão 3.00); (2) Gráficos via programa Gretl (versão 1.9.7). 


\section{CONCLUSÃO}

Este artigo levou em consideração a possibilidade da existência de assimetrias na direção, na velocidade e na dimensão das respostas das políticas econômicas. Para tanto, foi verificado o comportamento dos componentes da política fiscal (impulso fiscal e regra fiscal) frente ao ciclo econômico, bem como o comportamento da política monetária.

A análise descritiva preliminar realizada para averiguar uma possível existência de assimetrias mostrou que, durante todo o período estudado, a economia brasileira passou por quatro períodos de aceleração e três de desaceleração. Vale salientar que períodos de desaceleração (ou aceleração) econômica foram definidos como sendo períodos onde o hiato do produto observado foi menor (ou maior) que 0,5 desvio padrão.

Os resultados dessa análise preliminar revelaram indícios importantes de não linearidade nas respostas fiscais e monetárias do governo, uma vez que as políticas econômicas comportaram-se de forma distinta frente aos diferentes cenários (houve diferenças tanto nas frequências quanto nos prazos das respostas). A política fiscal cíclica e a política monetária foram mais frequentemente utilizadas durante as acelerações, ou seja, durante períodos de melhor desempenho da economia a autoridade fiscal agiu menos discricionariamente que nos períodos de desaceleração. Esse comportamento pode sugerir que o governo eleve seus gastos líquidos durante as desacelerações mas não os reduz na mesma proporção nas acelerações. Ou seja, o governo aparentemente se preocupa mais com as reduções do produto.

O Banco Central, por sua vez, age mais ativamente quando a economia encontra-se aquecida. Esse comportamento pode ser um reflexo da maior preocupação da autoridade monetária com a pressão inflacionária que surge em um ambiente de maior atividade econômica. Após essa análise descritiva, foi realizada a modelagem econométrica considerando a presença de assimetrias na condução da política, via inclusão da possibilidade da existência de não linearidades na modelagem econométrica. Para esta tarefa, foi utilizado o modelo VAR com mudanças de regime markovianos (MS-VAR).

Os testes de linearidade realizados mostraram que existem assimetrias na política fiscal e monetária, sinalizando que os formuladores de políticas podem reagir de maneira assimétrica à períodos de crescimento e retração econômica, ou seja, promoverem políticas de afrouxamento em períodos de recessão e não adotarem políticas suficientemente restritivas em períodos de crescimento.

As respostas das variáveis fiscais e monetárias foram analisadas quando dado choques negativos de uma unidade na variação do hiato do produto. Observou-se que a regra é a política mais veloz (com base em todas as metodologias). Isso é o esperado, uma vez que a regra é o estabilizador automático do ciclo econômico, assim, o balanço fiscal cíclico (ou automático) aumenta e reduz à medida que a economia cresce ou decresce. Além disso, por esse mesmo motivo, a regra apresenta menor assimetria quando comparada as demais políticas.

A política monetária parece reagir mais fortemente às variações positivas do hiato (isso só não ocorre com base no método Holandês), o que sugere que o Banco Central se preocupa majoritariamente com a pressão inflacionária que o crescimento da economia pode gerar.

\section{BIBLIOGRAFIA}

Alesina, A. \& Bayoumi, T. (1996). The costs and benefits of fiscal rules: Evidence from U.S. States. NBER Working Paper 5614, National Bureau of Economic Research, Cambridge.

Alesina, A., Campante, F. R., \& Tabellini, G. (2008). Why is fiscal policy often procyclical? Journal of the European Economic Association, 6(5):1006-1036.

Balassone, F., Francese, M., \& Zotteri, S. (2008). Cyclical asymmetry in fiscal variables. In Temi di Discussione, number 671. Banca D’Italia. 
Caballero, R. J. \& Krishnamurthy, A. (2004). Fiscal policy and financial depth. NBER Working Paper 10532, National Bureau of Economic Research, Cambridge.

Chand, S. K. (1992). Fiscal impulses and their fiscal impact. IMF Working Paper 92/38, International Monetary Fund, Washington.

Claessens, S., Kose, M. A., \& Terrones, M. E. (2008). What happens during recessions, crunches and busts? IMF Working Paper 08/274, International Monetary Fund, Washington.

Ehrmann, M., Ellison, M., \& Valla, N. (2003). Regime-dependent impulse response functions in a Markovswitching vector autoregression model. Economics Letters, 78(3):295-299.

FMI (2006). Regional economic outlook: Western hemisphere. In World Economic and Financial Surveys. International Monetary Fund, Washington, DC.

Gavin, M. \& Perotti, R. (1997). Fiscal Policy in Latin America, pages 11-72. NBER Macroeconomics Annual, MIT Press.

Girouard, N. \& André, C. (2005). Measuring cyclically-adjusted budget balances for OECD countries. OECD Economics Departament Working Papers 6434, Organisation for Economic Co-operation and Development.

Heller, P. S., Haas, R. D., \& Mansur, A. S. (1986). A review of the fiscal impulse measure. In International Monetary Fund, W., editor, FMI Occasional Paper, number 44.

Hercowitz, Z. \& Strawczynski, M. (2004). Cyclical ratcheting in government spending: Evidence from the OECD. The Review of Economics and Statistics, 86(1):353-361.

Ilzetzki, E. (2008). Rent-seeking distortions and fiscal procyclicality. In MPRA Paper, number 11900.

Ilzetzki, E. \& Végh, C. A. (2008). Procyclical fiscal policy in developing countries: Truth or fiction? NBER Working Paper 14191, National Bureau of Economic Research, Cambridge.

Kim, C.-J. \& Nelson, C. R. (1999). State-space models with regime switching: Classical and gibbs-sampling approaches with applications. Technical report, Cambridge: The MIT Press.

Krolzig, H.-M. (1998). Econometric modelling of markov-switching vector autoregression using MSVAR for Ox. In Discussion Paper. Departament of Economics, University of Oxford.

Leigh, D. \& Stehn, S. J. (2009). Fiscal and monetary policy during downturns: Evidence from the G7. In IMF Working Paper, number 09/50. International Monetary Fund, Washington.

Mayr, K. \& Scharler, J. (2009). Asymmetric fiscal stabilization policy and the public deficit: Theory and evidence. In Working Paper, number 0908. University of Vienna.

Mendoza, E. G. \& Oviedo, M. (2006). Fiscal policy and macroeconomic uncertainty in developing countries: The tale of the tormented insurer. In NBER Working Paper, number 12586. National Bureau of Economic Research, Cambridge.

OCDE (2003). Fiscal stance over the cycle: The role of debt, institutions, and budget constraints. OECD Economic Outlook 74, Organisation for Economic Co-Operation and Development.

Orphanides, A. \& Wieland, V. (1998). Price stability and monetary policy effectiveness when nominal interest rates are bounded at zero. In Finance and Economics Discussion Series, number 35. Board of Governors of the Federal Reserve System. 
Reifschneider, D. L. \& Williams, J. C. (1999). Three lessons for monetary policy in a low inflation era. In Finance and Economics Discussion Series, number 44. Board of Governors of the Federal Reserve System.

Rocha, F. (2009). Política fiscal através do ciclo e operação dos estabilizadores fiscais. Revista da ANPEC, Brasília, 10(2):357-372.

Rocha, F. \& Giuberti, A. C. (2008). Assimetria cíclica na política fiscal dos estados brasileiros. Pesquisa e Planejamento Econômico, 38(2):253-275.

Sidaoui, J. (2003). Implications of fiscal issues for central banks: Mexico's experience. BIS Papers, Bank for International Settlements, (20):180-197.

Sorensen, B. E. \& Yosha, O. (2001). Is state fiscal policy asymmetric over the business cycle? Economic Review, Federal Reserve Bank of Kansas City, 2001(3):43-64.

Talvi, E. \& Végh, C. A. (2005). Tax base variability and procyclical fiscal policy in developing countries. Journal of Development Economics, 78(1):156-190.

Tornell, A. \& Lane, P. R. (1999). The voracity effect. The American Economic Review, 89(1):22-46. 


\section{A. APÊNDICE}

\section{A.1. Metodologias Para a Filtragem dos Componentes da Política Fiscal}

\section{Metodologia da OCDE}

Na metodologia utilizada pela $\mathrm{OCDE}^{14}$ o balanço ciclicamente ajustado, em relação ao produto potencial, $B^{*}$, é definido como:

$$
B^{*}=\frac{\left[T^{*}-G^{*}+X\right]}{Y^{*}}
$$

onde $G^{*}$ representa o gasto primário corrente do governo ciclicamente ajustado, $T_{i}^{*}$ representa o componente ciclicamente ajustado das receitas do governo, $X$ representa as receitas não provenientes de impostos menos os gastos de capital e juros e $Y^{*}$ representa o nível do produto potencial.

Os componentes ciclicamente ajustados são calculados a partir da receita corrente proveniente da cobrança de impostos $(T)$ e dos gastos do governo $(G)$. A receita é ajustada pela razão entre o produto potencial $\left(Y^{*}\right)$ e o produto corrente $(Y)$ e pela elasticidade da receita em relação ao hiato do produto $\left(\epsilon_{t, y}\right)$. Já os gastos são ajustados pela razão entre o desemprego estrutural $\left(U^{*}\right)$ e o desemprego corrente $(U)$ e pela elasticidade do gasto primário corrente em relação a razão entre o desemprego estrutural e o corrente $\left(\epsilon_{g, u}\right)$. Algebricamente, tem-se:

$$
\begin{aligned}
\frac{T^{*}}{T} & =\left(\frac{Y^{*}}{Y}\right)^{\epsilon_{t, y}} \\
\frac{G^{*}}{G} & =\left(\frac{U^{*}}{U}\right)^{\epsilon_{g, u}}
\end{aligned}
$$

Substituindo as equações (A2) e (A3) em (A1) obtém-se o balanço ciclicamente ajustado, ou seja:

$$
B^{*}=\frac{\left[T\left(\frac{Y^{*}}{Y}\right)^{\epsilon_{t, y}}-G\left(\frac{U^{*}}{U}\right)^{\epsilon_{g, u}}+X\right]}{Y^{*}}
$$

A primeira diferença de $B^{*}$ na equação (A4) representa o impulso fiscal, ou seja:

$$
I F_{t}^{O C D E}=\Delta B^{*}
$$

\section{Metodologia FMI (2006)}

Para a obtenção dos componentes de regra e discrição através dessa metodologia é preciso definir as despesas e receitas ciclicamente neutras. Conforme observam Heller et alii (1986), a despesa é considerada como sendo ciclicamente neutra quando a mesma responde proporcionalmente às elevações no produto potencial. Já a receita ciclicamente neutra é aquela que responde proporcionalmente às variações no produto observado. Algebricamente podemos representar essas relações da seguinte forma:

$$
\begin{aligned}
G_{t}^{*} & =\frac{G_{0}}{Y_{0}^{p}} Y_{t}^{p} \\
T_{t}^{*} & =\frac{T_{0}}{Y_{0}^{p}} Y_{t}
\end{aligned}
$$

\footnotetext{
${ }^{14}$ Maiores detalhes sobre esta metodologia podem ser encontrados em Girouard e André (2005).
} 
onde $G$ e $T$ representam as despesas e as receitas do governo, $Y$ representa o produto e $Y^{p}$ o produto potencial. Para o cálculo dos componentes ciclicamente neutros $\left(G^{*}\right.$ e $\left.T^{*}\right)$ é necessário que se escolha um ano base onde o produto observado seja igual ao potencial. Para obter os gastos e a arrecadação do governo ciclicamente ajustados basta subtrair os componentes ciclicamente neutros dos gastos e das receitas, ou seja: $G_{t}^{c a}=G_{t}-G_{t}^{*}$ e $T_{t}^{c a}=T_{t}-T_{t}^{*}$.

o impulso fiscal, ou seja, a elevação líquida dos gastos do governo que não dependem do ciclo econômico, é obtido através da variação do balanço orçamentário do governo ciclicamente ajustado (em relação ao PIB):

$$
\begin{gathered}
I F_{t}=\left(\frac{\Delta G_{t}-\Delta G_{t}^{*}}{Y_{t}}\right)-\left(\frac{\Delta T_{t}-\Delta T_{t}^{*}}{Y_{t}}\right) \\
I F_{t}^{F M I(2006)}=\left[\Delta\left(\frac{G_{t}}{Y_{t}}\right)-\Delta\left(\frac{\left(\frac{G_{0}}{Y_{0}^{P}}\right) Y_{t}^{P}}{Y_{t}}\right)\right]-\left[\Delta\left(\frac{T_{t}}{Y_{t}}\right)-\Delta\left(\frac{\left(\frac{T_{0}}{Y_{0}^{P}}\right) Y_{t}}{Y_{t}}\right)\right]
\end{gathered}
$$

\section{Método Holandês}

Outra forma para calcular o impulso fiscal, chamado de método Holandês, é apresentada por Sidaoui (2003). Tal método é uma variação do método FMI (2006), considerando que o período base para o cálculo é igual ao período imediatamente anterior:

$$
I F_{t}^{\text {Holandês }}=\left[\Delta\left(\frac{G_{t}}{Y_{t}}\right)-\Delta \frac{\left(\frac{G_{t-1}}{Y_{t-1}^{P}}\right) Y_{t}^{P}}{Y_{t}}\right]-\left[\Delta\left(\frac{T_{t}}{Y_{t}}\right)-\Delta \frac{\left(\frac{T_{t-1}}{Y_{t-1}^{P}}\right) Y_{t}}{Y_{t}}\right]
$$

De acordo com Chand (1992) uma vantagem do método Holandês é o fato do mesmo não depender da escolha do ano base, ou seja, o impulso fiscal é determinado utilizando como referência o balanço fiscal do período imediatamente anterior.

\section{Metodologia FMI (2008)}

FMI (2008) constrói uma medida de impulso fiscal a partir da estimação de um conjunto de regressões considerando o crescimento real do PIB como uma proxy para o ambiente econômico. Nessa metodologia o balanço do governo no período $t$ pode ser expresso como uma função da política fiscal discricionária, $P_{t}$, e do ambiente econômico prevalecente no período, $E_{t}$. Assim: $B_{t}=B\left(P_{t}, E_{t}\right)$. A mudança do balanço fiscal em relação ao ano anterior pode ser representada da seguinte forma:

$$
\Delta B_{t}=B\left(P_{t}, E_{t}\right)-B\left(P_{t-1}, E_{t-1}\right)
$$

Somando e subtraindo o termo $B\left(P_{t}, E_{t-1}\right)$, que representa qual seria o balanço fiscal resultante de uma política no tempo $t$ caso o ambiente econômico se mantivesse inalterado entre $t-1$ e $t$, obtém-se:

$$
\Delta B_{t}=\Delta B_{t}^{E}+\Delta B_{t}^{P}
$$

O termo $\Delta B_{t}^{E}$ representa os efeitos fiscais das mudanças no ambiente econômico de $E_{t-1}$ para $E_{t}$. Nesse caso não há mudanças discricionárias na política fiscal entre o tempo $t-1$ e o tempo $t$, ou seja, $P$ não se altera.

Já o termo $\Delta B_{t}^{P}$ captura mudanças no balanço resultante de mudanças na política discricionária. Aqui ocorre uma mudança na política fiscal, $P$, mesmo que o ambiente econômico permaneça inalterado.

Como o balanço é o resultado da subtração entre as receitas e despesas do governo, para mensurar o impulso fiscal é preciso estimar as seguintes equações para estas variáveis: 


$$
\begin{aligned}
& T_{t}=\alpha_{R}+\beta_{R}\left(\text { cresc }_{t}\right)+\gamma_{R} t+u_{t} \\
& G_{t}=\alpha_{E}+\beta_{E}\left(\text { cresc }_{t}\right)+\gamma_{E} t+e_{t}
\end{aligned}
$$

onde $T$ é a receita em porcentagem do PIB, $G$ é a despesa do governo como percentagem do PIB, o cresc é o crescimento do PIB real e $t$ representa uma tendência temporal. Os termos $u$ e $e$ indicam os resíduos da estimação.

Assim, a receita e a despesa ciclicamente ajustadas são dadas pelas equações (A14) e (A15), que por sua vez mostram qual seria o valor dessas variáveis caso a taxa de crescimento do produto não apresentasse variação em relação ao tempo $t-1$.

$$
\begin{aligned}
& T_{t}\left(\operatorname{cresc}_{t-1}\right)=\hat{\alpha_{R}}+\hat{\beta_{R}}\left(\operatorname{cresc}_{t-1}\right)+\hat{\gamma_{R}} t+\hat{u_{t}} \\
& G_{t}\left(\operatorname{cresc}_{t-1}\right)=\hat{\alpha_{E}}+\hat{\beta_{E}}\left(\operatorname{cresc}_{t-1}\right)+\hat{\gamma_{E}} t+\hat{{\theta_{t}}_{t}}
\end{aligned}
$$

Dessa forma, a diferença entre as equações (A14) e (A15) consiste no balanço fiscal ciclicamente ajustado, que ao ser diferenciado fornece uma medida para o impulso fiscal.

$$
I F_{t}^{\mathrm{FMI}(2008)}=\left(\hat{\gamma}_{R}-\hat{\gamma}_{E}\right)+\left(\hat{u}_{t}-\hat{u}_{t-1}\right)-\left(\hat{e}_{t}-\hat{e}_{t-1}\right)
$$

\section{Filtro de Kalman}

Outra forma de decompor a política fiscal, para obter o seu componente automático e o seu componente discricionário, pode ser realizada considerando que o peso dado pelo governo aos desvios do produto em relação ao seu nível potencial varia ao longo do tempo. Para tanto se utiliza o filtro de Kalman. ${ }^{15}$

Considerando que a política fiscal consiste na variação do superávit do governo, $B_{t}-B_{t-1}=\Delta B_{t}$, tem-se:

$$
\begin{aligned}
& \Delta B_{t}=\rho_{t}+\varepsilon_{t} \\
& \rho_{t}=\beta_{t} \Delta \text { gap }_{t} \\
& \beta_{t}=\beta_{t-1}+\eta_{t}
\end{aligned}
$$

A equação (A17) informa que a política fiscal é composta por dois componentes, $\rho_{t}$ e $\varepsilon_{t}$. O componente $\rho_{t}$ é uma função de mudanças no ciclo econômico (representado pela variação do hiato do produto, $\Delta g a p_{t}$ ), conforme descrito na equação (A18). Onde os resíduos da regressão seguem uma distribuição normal e são idêntica e normalmente distribuídos, ou seja, $\epsilon_{t} i i n\left(0, \sigma_{\varepsilon}^{2}\right)$.

Diferentemente das metodologias da OCDE, FMI (2006) e FMI (2008), aqui o impacto do ciclo econômico sobre a política fiscal não é constante, ou seja, o $\beta$ da equação (A18) varia. A intuição sobrejacente é a de que a autoridade fiscal pode mudar o peso dado às flutuações no hiato do produto ao longo do tempo.

\section{A.2. Sequência de Comandos Gretl}

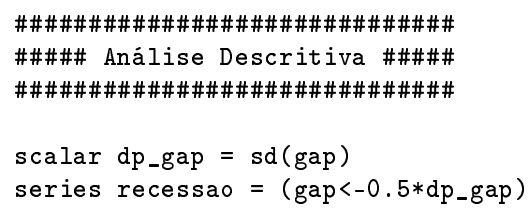

\footnotetext{
${ }^{15}$ Uma boa introdução aos modelos de espaço de estados e ao filtro de Kalman pode ser encontrada em Kim e Nelson (1999).
} 
series aceleracao $=($ gap $>0.5 *$ dp_gap $)$

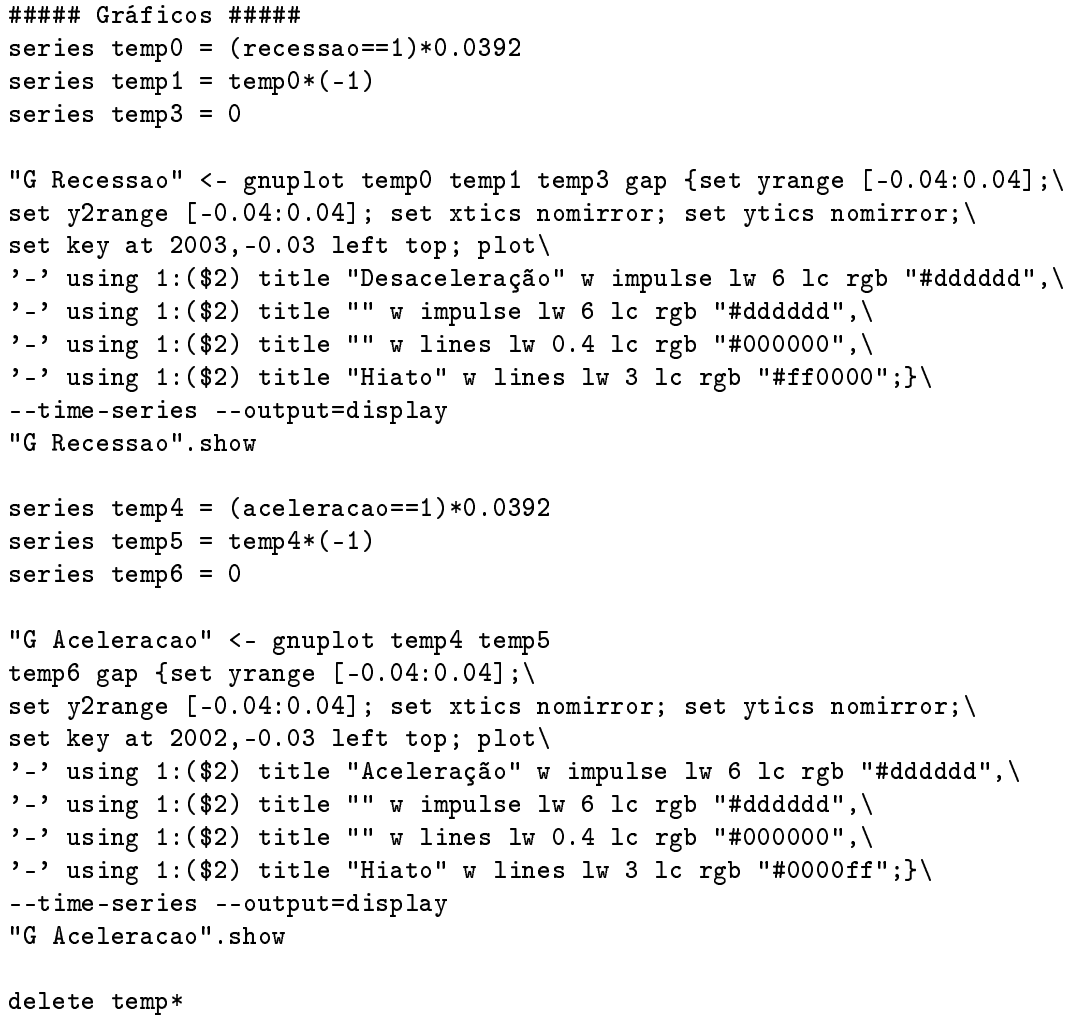




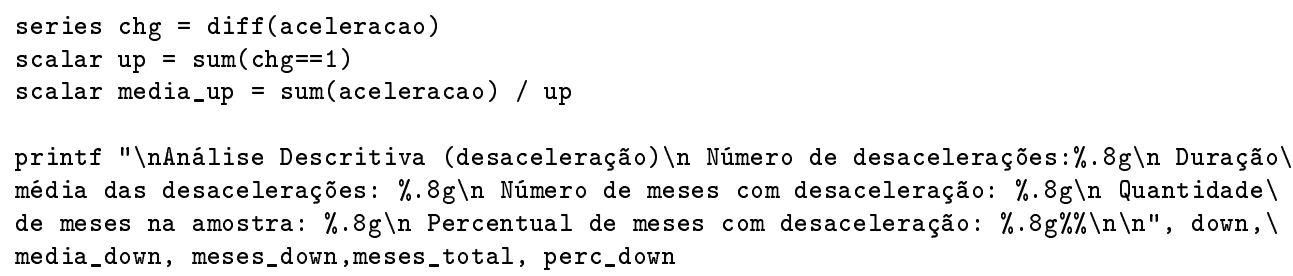




\section{A.3. Sequência de Comandos $0 x$}

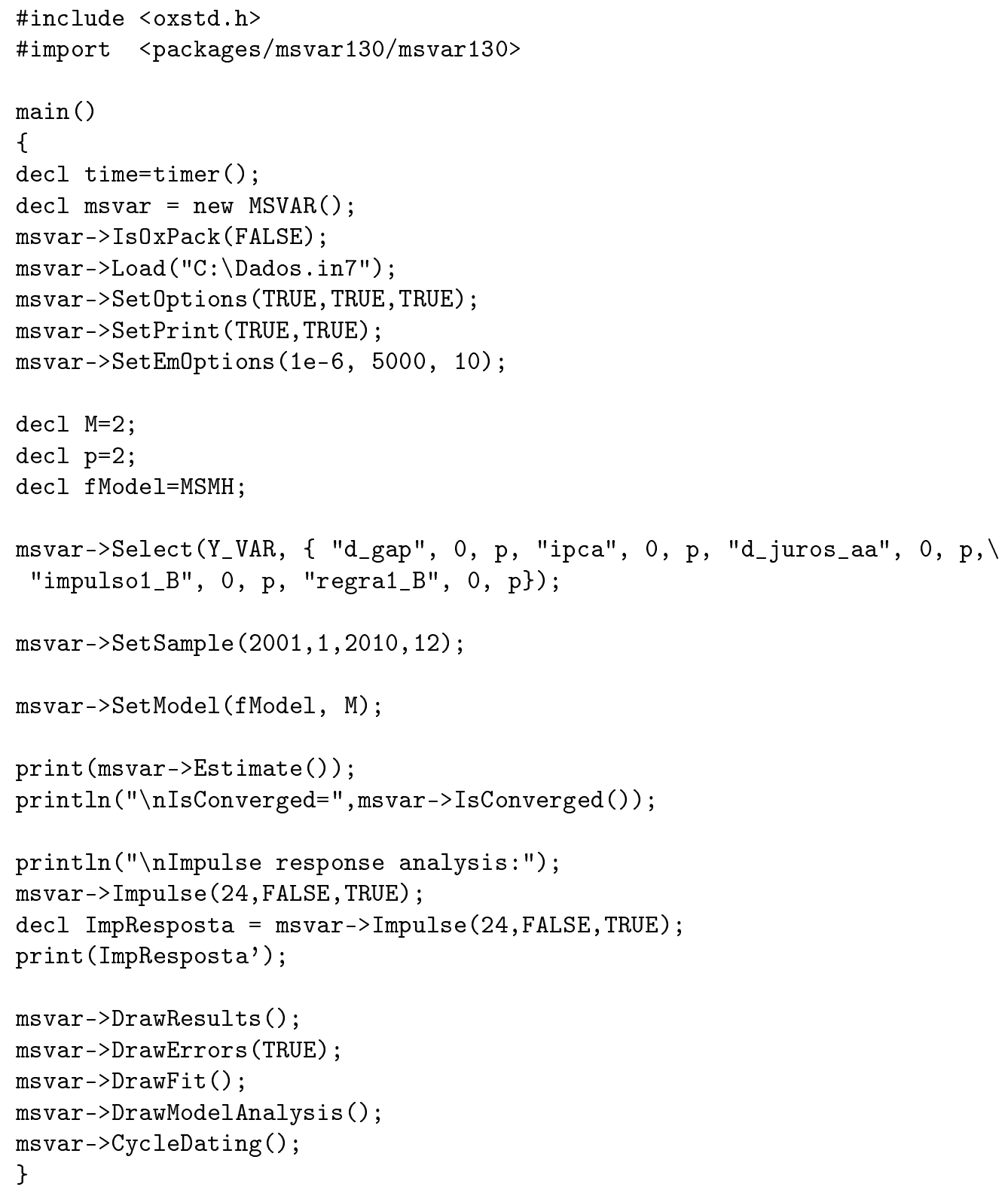

